\title{
EVALUASI CEPAT DESAIN ELEMEN BALOK BETON BERTULANGAN TUNGGAL BERDASARKAN RASIO TULANGAN BALANCED
}

\author{
Agus Setiawan \\ Jurusan Teknik Sipil, Fakultas Ilmu Komputer, Universitas Bina Nusantara \\ Jln. K.H. Syahdan No. 9, Palmerah, Jakarta Barat 11480 \\ agustinusset@yahoo.com
}

\begin{abstract}
Design procedure for reinforced concrete structure in Indonesia is provided by "Tata Cara Perhitungan Struktur Beton, SNI 03-2847-2002". This code covers analysis method and basic assumptions that can be taken by a structural designer to design a reinforced concrete structure. An engineer has to design a flexural component, one of the structural component. One of the flexural component is beam element. SNI 03-2847-2002 adopt capacity design menthod in beam element design. This paper will be discuss a simple design procedure in beam element, based on $\xi$ variabel, which is ratio between $\rho / \rho_{b}$, with $\rho_{b}$ is the balanced reinforcement ratio. The $\xi$ value is limited to 0,75 maximum in SNI 03-2847-2002. A dactail failure is guarantee in a beam element with $\xi$ under 0,75. The analysis that have been done before, produce the correlation between $M_{n} / b d^{2}$ and $\xi$, which can be a tool for design a beam element. A simple calculation use the table $\left(M_{n} / b d^{2} v s \xi\right)$ will be present at the end of this paper.
\end{abstract}

Keywords: beam, balanced, SNI 03-2847-2002, dactail

\begin{abstract}
ABSTRAK
Prosedur desain untuk struktur beton bertulang telah diatur dalam "Tata Cara Perhitungan Struktur Beton, SNI 03-2847-2002”. Peraturan ini mencakup metode-metode analisis dan asumsi asumsi dasar yang dapat diambil oleh seorang perencana struktur untuk merencanakan suatu struktur beton bertulang. Soerang perencana umumnya harus mendesain suatu komponen lentur yang merupakan salah satu dari komponen struktur yang ada. Salah satu komponen lentur tersebut adalah elemen balok. SNI 03-2847-2002 mengadopsi konsep desain kapasitas dalam perencanaan suatu elemen balok. Makalah ini hendak membahas suatu prosedur sederhana dalam perencanaan elemen balok, berdasarkan variabel $\xi$, yang merupakan rasio anatar $\rho / \rho_{b}$, dengan $\rho_{b}$ adalah rasio tulangan dalam kondisi seimbang. Nilai $\xi$ dalam SNI 03-2847-2002 dibatasi maksimum 0,75. Dengan mengambil nilai $\xi$ di bawah 0,75, maka dapat dipastikan tipe keruntuhan yang terjadi adalah daktail. Analisis yang telah dilakukan menghasilkan hubungan $M_{n} / b d^{2}$ dengan $x$, yang dapat digunakan sebagai alat bantu dalam perencanaan elemen balok beton bertulang. Pada akhir makalah diberikan contoh sederhana pemakaian tabel hubungan $M_{n} / b d^{2}$ dan $\xi$.
\end{abstract}

Kata kunci: balok, seimbang, SNI 03-2847-2002, daktail 


\section{PENDAHULUAN}

Beton bertulang merupakan material yang banyak digunakan dalam dunia konstruksi baik itu di Indonesia maupun di dunia internasional. Kajian-kajian terkait dengan metode-metode dalam perencanaan struktur beton bertulang terus dilakukan secara berkesinambungan guna mencapai hasil desain yang aman dari segi kekuatan namun juga ekonomis dari segi biaya. Guna menjamin profesionalitas dalam hal perencanaan struktur beton bertulang di Indonesia, maka sejak tahun 2002, telah dikeluarkan peraturan “Tata Cara Perhitungan Struktur Beton, SNI 03-2847-2002”. Segala hal terkait perencanaan struktur beton hendaknya mengacu pada peraturan ini.

Salah satu komponen struktur yang dapat dijumpai dalam suatu perencanaan struktur beton bertulang adalah berupa komponen struktur lentur. Balok merupakan salah satu komponen struktur lentur yang banyak ditemui dalam suatu proses perencanaan struktur. Dalam kaidah perencanaan elemen balok, hendaknya desain dilakukan sedemikian rupa sehingga terjadi keruntuhan daktail pada elemen tersebut. Keruntuhan daktail tercapai apabila tulangan baja mengalami leleh terlebih dahulu sebelum penampang beton mengalami regangan ultimitnya sebesar 0,003 .

Untuk menjamin tercapainya perilaku keruntuhan yang daktail dari suatu elemen balok, maka dalam SNI 03-2847-2002 disyaratkan bahwa rasio tulangan tarik harus lebih kecil dari 0,75 dikali rasio tulangan dalam kondisi berimbang/balance, atau secara matematis dalam peraturan dinyatakan bahwa $\rho_{\text {maks }} \leq 0,75 \rho_{\mathrm{b}}$.

Namun pada prakteknya, secara umum nilai $\rho$ diambil kurang dari $0,75 \rho_{\mathrm{b}}$, semakin kecil rasio tulangan terhadap $\rho_{\mathrm{b}}$, maka akan lebih terjamin terjadinya perilaku daktail dari elemen balok. Namun nilai $\rho$ tidak boleh diambil terlalu kecil sehingga menghasilkan luas tulangan yang lebih kecil daripada luas tulangan minimum yang disyaratkan dalam SNI. Dalam uraian-uraian berikut akan dibahas nilai $\rho$ yang dapat diambil (dalam rasio terhadap $\rho_{\mathrm{b}}$ ) sehingga dapat menghasilkan desain elemen balok yang aman dari segi kekuatan namun juga ekonomis dari segi biaya.

\section{METODE PENELITIAN}

Untuk merumuskan suatu persamaan yang akan digunakan dalam evaluasi cepat desain elemen balok beton bertulang berdasarkan rasio tulangan balanced, makan perlu dilakukan studi literatur mengenai analisis balok beton tulangan tunggal secara konvensional. Dasar dalam melakukan analisis balok beton tulangan tunggal dilakukan berdasarkan Tata Cara Perhitungan Struktur Beton, SNI 03-2847-2002.

\section{Asumsi Dasar Perencanaan Elemen Lentur Balok Beton Bertulangan Tunggal}

SNI 03-2847-2002 mencantumkan asumsi-asumsi dasar yang digunakan dalam hal perencanaan elemen lentur (balok). Asumsi-asumsi yang digunakan dalam perencanaan komponen struktur lentur adalah sebagai berikut. Pertama, regangan pada tulangan dan beton dianggap berbanding lurus terhadap sumbu netral. Kedua, regangan pada serat tekan beton terluar diambil sama dengan 0,003 . Ketiga, tegangan tarik pada tulangan yang kurang dari $f_{\mathrm{y}}$ harus diambil sebesar $E_{\mathrm{s}}$ dikali regangan tulangan, sedangkan regangan tulangan yang melebihi $f_{\mathrm{y}}$ harus diambil sama dengan $f_{\mathrm{y}}$. Keempat, kuat tarik beton harus diabaikan dalam perhitungan aksial dan lentur. Kelima, hubungan antara distribusi tegangan tekan beton dan regangan beton diasumsikan berbentuk segi empat, parabola, trapesium atau bentuk lain yang sesuai dengan hasil pengujian. Keenam, tegangan tekan 
beton sebesar $0,85 f^{\prime}$ c diasumsikan terdistribusi merata pada area tekan ekivalen yang dibatasi oleh tepi penampang dan garis sejarak $a=\beta_{1}$.c dari sisi terluar serat tekan beton. Ketujuh, jarak $c$ dari serat dengan regangan maksimum ke sumbu netral, diukur tegak lurus sumbu tersebut. Kedelapan, faktor $\beta_{1}$ harus diambil sebesar 0,85 untuk kuat tekan beton kurang atau sama dengan $30 \mathrm{MPa}$, dan direduksi sebesar 0,05 untuk tiap kelebihan $7 \mathrm{MPa}$ di atas $30 \mathrm{MPa}$, namun tidak kurang dari 0,65.

\section{Analisis Balok Beton Tulangan Tunggal}

Dalam analisis balok beton bertulangan tunggal dikenal istilah kondisi balanced, atau suatu kondisi di mana beton mencapai regangan maksimum sebesar 0,003 dan diikuti oleh tulangan tarik yang mencapai tegangan lelehnya, $f_{\mathrm{y}}$. Rasio tulangan pada kondisi balanced, $\rho_{\mathrm{b}}$, dijadikan patokan untuk menentukan rasio tulangan maksimum dalam elemen balok.

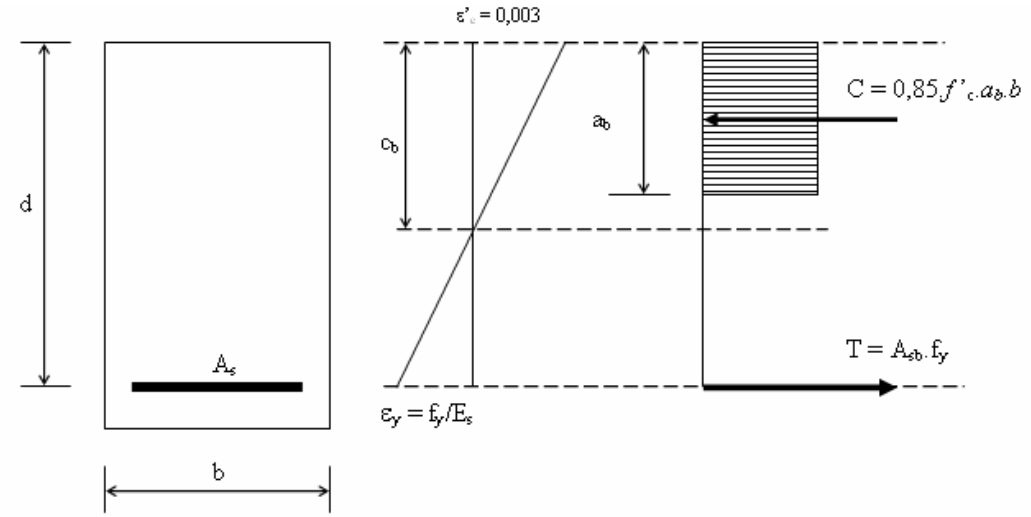

Gambar 1 Kondisi Balance Balok Beton Persegi Bertulangan Tunggal hubungan:

Dari diagram regangan, dengan menggunakan prinsip perbandingan segitiga diperoleh

$$
\frac{c_{b}}{d-c_{b}}=\frac{0,003}{f_{y} / E_{S}}
$$

Atau dapat dituliskan persamaan untuk $c_{\mathrm{b}}$ sebagai berikut:

$$
c_{\mathrm{b}} \quad=\frac{0.009}{0.003+f_{\mathrm{y}} / E_{\mathrm{b}}} \times d
$$

Dengan menganggap nilai $\mathrm{E}_{\mathrm{s}}=200.000 \mathrm{MPa}$, maka:

$$
c_{\mathrm{b}} \quad=\frac{6 \mathrm{ecl}}{600+f_{\mathrm{y}}} \times d
$$

Dari keseimbangan gaya diperoleh hubungan:

$$
\begin{gathered}
\mathrm{C}=\mathrm{T} \\
\text { 0,85. } f^{\prime} \text { c. } a_{\mathrm{b}} \cdot b=A_{\mathrm{sb}} \cdot f_{\mathrm{y}}
\end{gathered}
$$

sehingga diperoleh:

$$
a_{\mathrm{b}}=\frac{A_{g b} \cdot f_{y}}{0,95 \cdot f_{c}^{f} \cdot b}=\frac{\rho b \cdot b \cdot d \cdot f_{y}}{0,93 \cdot f_{c}^{f} \cdot b}
$$

dengan mengingat bahwa $a_{\mathrm{b}}=\beta_{1} \cdot c_{\mathrm{b}}$, maka persamaan untuk $\rho_{\mathrm{b}}$ dapat dituliskan: 


$$
\rho_{\mathrm{b}}=0,85, \beta_{2}=\frac{t_{E}^{k}}{f_{b}} \cdot\left(\frac{6000}{600+f_{5}}\right)
$$

Gambar 2 menunjukkan penampang beton bertulangan tunggal berikut blok diagram tegangannya. Dengan notasi $\xi$ adalah perbandingan antara rasio tulangan terpasang dengan rasio tulangan pada kondisi balanced $\left(\xi=\rho / \rho_{\mathrm{b}}\right)$.

Dari keseimbangan gaya diperoleh hubungan :

$$
0,85 \cdot f^{\prime}{ }_{c} \cdot a \cdot b=\xi \cdot \rho_{\mathrm{b}} \cdot b \cdot d \cdot f_{\mathrm{y}}
$$

Dari persamaan tersebut, maka nilai a dapat dihitung:

$$
\mathrm{a}=\xi \cdot \beta_{1} \cdot \frac{600}{600+f_{y}} \times d
$$
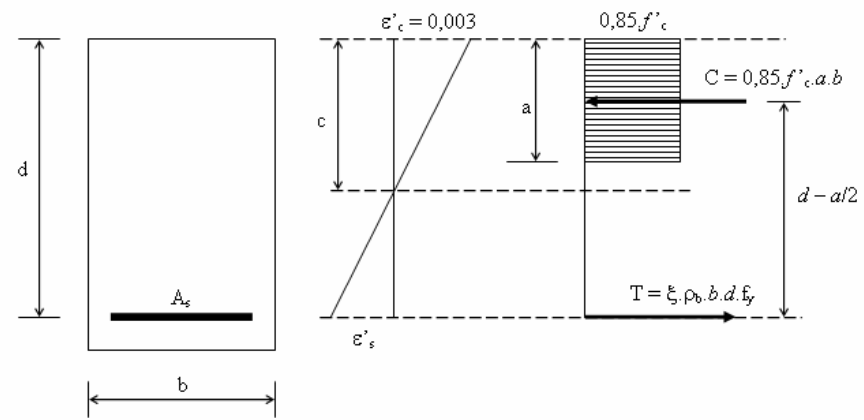

Gambar 2 Keseimbangan Gaya dalam Penampang Balok Beton Bertulangan Tunggal

Momen nominal internal yang timbul adalah:

$$
\begin{aligned}
M_{\mathrm{n}} & =\mathrm{C}(d-a / 2) \\
& =0,85 \cdot f^{\prime}{ }^{\prime} \cdot a \cdot b(d-a / 2)
\end{aligned}
$$

Dengan substitusi nilai a, maka persamaan untuk momen internal adalah:

$$
M_{\mathrm{n}} \quad=0,85 \cdot f^{\prime} \cdot \beta_{1} \cdot b \cdot d^{2} \cdot\left(\frac{600}{600+f_{y}}\right) \xi-\frac{0,85 \cdot f_{c}^{\prime} \beta_{1}^{2} \cdot b \cdot d^{2}}{2}\left(\frac{600}{600+f_{y}}\right)^{2} \xi^{2}
$$

\section{HASIL DAN PEMBAHASAN}

Dari hasil analisis momen internal dalam suatu balok beton bertulangan tunggal, akhirnya dapat diturunkan suatu rumusan umum seperti dalam persamaan (7). Guna keperluan desain, maka persamaan tersebut dapat disederhanakan dengan mengasumsikan bahwa mutu tulangan lentur, $f_{\mathrm{y}}$, yang umum dijumpai di Indonesia adalah $f_{\mathrm{y}}=400 \mathrm{MPa}$. Selanjutnya untuk baja tulangan dengan kuat leleh $f_{\mathrm{y}}=400 \mathrm{MPa}$, maka persamaan dapat disederhanakan menjadi:

$$
M_{\mathrm{n}}=0,51 \cdot f^{\prime}{ }^{\prime} \cdot \beta_{1} \cdot b \cdot d^{2} \cdot \xi-0,153 \cdot f^{\prime}{ }^{\prime} \cdot \beta_{1}{ }^{2} \cdot b \cdot d^{2} \cdot \xi^{2}
$$

Atau dapat dituliskan dalam bentuk :

$$
\frac{M_{n}}{b \cdot d^{2}}=0,51 \cdot f^{\prime} \cdot \beta_{1} \cdot \xi-0,153 \cdot f^{\prime} \cdot \beta_{1}^{2} \cdot \xi^{2}
$$


Persyaratan untuk tulangan minimum dalam suatu elemen lentur dijelaskan dalam SNI 032847-2002, pasal 12.5. Disebutkan bahwa:

$$
\mathrm{A}_{\mathrm{s} \min }=\frac{\sqrt{f_{c}}}{4 f_{y}}, b, d
$$

Namun tidak kurang dari :

$$
\mathrm{A}_{\mathrm{s} \min }=\frac{14}{8 y} \cdot \delta \cdot d
$$

Dengan mengingat bahwa $A_{\mathrm{s}}=\rho . b . d$, maka batasan $\rho$ minimum diambil dari nilai terkecil antara:

$$
\rho=\frac{\sqrt{f_{i}^{2}}}{4 f_{y}} \text { atau } \rho=\frac{14}{f_{y}}
$$
minimum:

Jika $\rho$ dinyatakan sebagai fraksi dari $\rho_{\mathrm{b}}$, atau $\rho=\xi . \rho_{\mathrm{b}}$, maka diperoleh batasan untuk $\xi$

$$
\begin{aligned}
\xi_{\min } & =\frac{\sqrt{f_{e}^{5}}}{4, f y p e} \\
\text { atau } \quad \xi_{\min } & =\frac{1.4}{f_{p y b}}
\end{aligned}
$$

Dengan mengingat bahwa $\rho_{\mathrm{b}}$ dapat dicari dari persamaan (5), dan dengan mengambil nilai $f_{\mathrm{y}}=$ $400 \mathrm{MPa}$, maka batasan untuk $\xi$ minimum adalah nilai terkecil dari :

$$
\xi_{\min }=\frac{1}{2.04 \times \beta_{2} \times \sqrt{f_{c}^{\prime \prime}}}
$$

Atau $\xi_{\text {min }}=\frac{2.8}{\forall_{1} \times \sqrt{f_{e}}}$

\section{Hubungan antara $M_{n} / b^{2}$ dengan Nilai $\xi$}

Hubungan antara $M_{\mathrm{n}} / b d^{2}$ dengan nilai $\xi$, telah diturunkan dalam persamaan (8). Dengan $M_{\mathrm{n}}$ adalah momen nominal dari elemen balok dalam satuan N.mm, yang diperoleh dari hasil analisis struktur, $b$ adalah lebar elemen balok dalam satuan $\mathrm{mm}$, dan $d$ adalah tinggi efektif balok dalam satuan mm. Hubungan tersebut dapat disajikan dalam bentuk tabel seperti dalam Tabel 1 berikut ini. Nilai $f^{\prime}{ }_{c}$ yang digunakan adalah dalam satuan MPa. Nilai $\beta_{1}$ terkait dengan nilai mutu beton, sesuai dengan asumsi dasar yang digunakan dalam perencanaan komponen struktur lentur. Secara matematis nilai $\beta_{1}$ dapat dituliskan dalam persamaan:

$$
\beta_{1}=0,85-\frac{f^{2}-30}{7} \cdot 0,0.5
$$

Hubungan antara $M_{\mathrm{n}} / b d^{2}$ dengan $\xi$, dapat ditampilkan dalam bentuk grafik seperti dalam Gambar 3 . 
Tabel 1 Hubungan antara $\mathrm{M}_{\mathrm{n}} / \mathrm{bd}^{2}$ dengan $\xi$

\begin{tabular}{|c|c|c|c|c|c|c|c|c|c|c|}
\hline & $f^{\prime} c$ & $\beta_{1}$ & $f^{\prime} c$ & $\beta_{1}$ & $f^{\prime} c$ & $\beta_{1}$ & $f^{\prime} c$ & $\beta_{1}$ & $f^{\prime} c$ & $\beta_{1}$ \\
\hline$\xi$ & $\begin{array}{c}20 \\
\mathrm{M}_{\mathrm{n}} / \mathrm{bd}^{2}\end{array}$ & $\begin{array}{c}0,85 \\
\rho \\
\end{array}$ & $\begin{array}{c}25 \\
M_{n} / b^{2}\end{array}$ & $\begin{array}{c}0,85 \\
\rho \\
\end{array}$ & $\begin{array}{c}30 \\
\mathrm{M}_{\mathrm{n}} / \mathrm{bd}^{2}\end{array}$ & $\begin{array}{c}0,85 \\
\rho \\
\end{array}$ & $\begin{array}{c}35 \\
\mathrm{M}_{\mathrm{n}} / \mathrm{bd}^{2}\end{array}$ & $\begin{array}{c}0,81 \\
\rho \\
\end{array}$ & $\begin{array}{c}40 \\
\mathrm{M}_{\mathrm{n}} / \mathrm{bd}^{2}\end{array}$ & $\begin{array}{c}0,78 \\
\rho \\
\end{array}$ \\
\hline 0,75 & 5,259 & 0,0163 & 6,574 & 0,0203 & 7,888 & 0,0244 & 8,904 & 0,0273 & 9,825 & 0,0298 \\
\hline 0,70 & 4,986 & 0,0152 & 6,232 & 0,0190 & 7,479 & 0,0228 & 8,435 & 0,0254 & 9,300 & 0,0278 \\
\hline 0,65 & 4,701 & 0,0141 & 5,877 & 0,0176 & 7,052 & 0,0211 & 7,948 & 0,0236 & 8,756 & 0,0258 \\
\hline 0,60 & 4,406 & 0,0130 & 5,508 & 0,0163 & 6,609 & 0,0195 & 7,443 & 0,0218 & 8,194 & 0,0238 \\
\hline 0,55 & 4,100 & 0,0119 & 5,125 & 0,0149 & 6,150 & 0,0179 & 6,920 & 0,0200 & 7,613 & 0,0218 \\
\hline 0,50 & 3,782 & 0,0108 & 4,728 & 0,0135 & 5,673 & 0,0163 & 6,380 & 0,0182 & 7,014 & 0,0199 \\
\hline 0,45 & 3,454 & 0,0098 & 4,317 & 0,0122 & 5,181 & 0,0146 & 5,822 & 0,0164 & 6,396 & 0,0179 \\
\hline 0,40 & 3,114 & 0,0087 & 3,893 & 0,0108 & 4,671 & 0,0130 & 5,246 & 0,0145 & 5,760 & 0,0159 \\
\hline 0,35 & 2,764 & 0,0076 & 3,455 & 0,0095 & 4,146 & 0,0114 & 4,652 & 0,0127 & 5,105 & 0,0139 \\
\hline 0,30 & 2,402 & 0,0065 & 3,003 & 0,0081 & 3,603 & 0,0098 & 4,041 & 0,0109 & 4,431 & 0,0119 \\
\hline 0,25 & 2,029 & 0,0054 & 2,537 & 0,0068 & 3,044 & 0,0081 & 3,412 & 0,0091 & 3,739 & 0,0099 \\
\hline 0,20 & 1,646 & 0,0043 & 2,057 & 0,0054 & 2,468 & 0,0065 & 2,765 & 0,0073 & 3,028 & 0,0079 \\
\hline
\end{tabular}

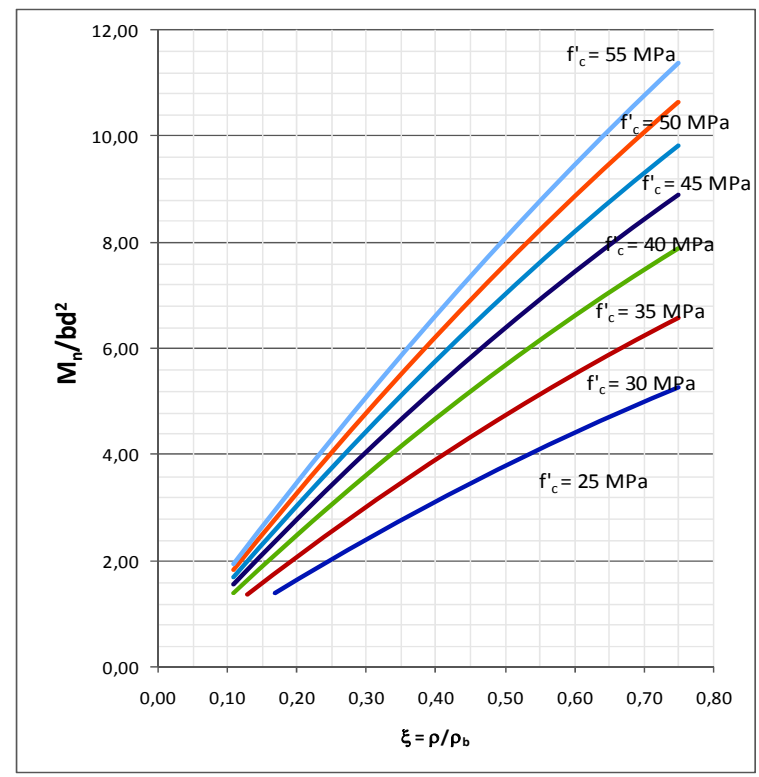

Gambar 3 Grafik Hubungan antara $\mathrm{M}_{\mathrm{n}} / \mathrm{bd}^{2}$ dengan Nilai $\xi=\mathrm{r} / \mathrm{r}_{\mathrm{b}}$

\section{Contoh Aplikasi Numerik}

Dalam uraian berikut diberikan contoh aplikasi penggunaan nilai $\xi$ dalam suatu perencanaan elemen balok, dengan data-data teknis sebagai berikut.

Mutu beton, $f{ }^{\prime}{ }_{\mathrm{c}} \quad=25 \mathrm{MPa}$

Mutu baja, $f_{\mathrm{y}} \quad=400 \mathrm{MPa}$

Beban merata ultimit, $q_{\mathrm{u}}=40 \mathrm{kN} / \mathrm{m}$

Panjang bentang, $L=9 \mathrm{~m}$

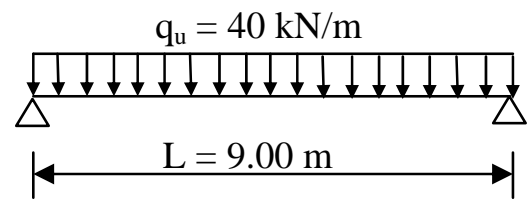

Dari data tersebut dapat dihitung momen ultimit maksimum di tengah bentang balok

$M_{\mathrm{u}} \quad=\frac{1}{\mathrm{~g}} \mathrm{q}_{\mathrm{u}} L^{2}=\frac{1}{\mathrm{~g}} \times 40 \times \mathrm{q}^{2}=405 \mathrm{kN} . \mathrm{m}$ 
$M_{\mathrm{n}} \quad=M_{\mathrm{u}} / \phi=\mathrm{M}_{\mathrm{u}} / 0,8 \quad=506,25 \mathrm{kN} \cdot \mathrm{m}$

Jika diambil nilai $\xi=0,45$ (atau berarti $\rho=0,45 \rho_{\mathrm{b}}$ ), dari tabel 1 , untuk mutu beton $f{ }^{{ }_{\mathrm{c}}}=25 \mathrm{MPa}$ diperoleh nilai $\mathrm{M}_{\mathrm{n}} / \mathrm{bd}^{2}=4,317$.

Dengan nilai $M_{\mathrm{n}}=506,25 \mathrm{kN} \cdot \mathrm{m}\left(=506,25 \cdot 10^{6} \mathrm{~N} \cdot \mathrm{mm}\right)$, maka:

$b d^{2}=\frac{806 \cdot 28 \cdot 10^{*}}{4.817}=117,27.106 \mathrm{~mm}^{3}$

Jika diambil nilai $b=300 \mathrm{~mm}$, diperoleh $d=625 \mathrm{~mm}$ atau diambil $\mathrm{h}=700 \mathrm{~mm}$, Rasio $b / \mathrm{h}=300 / 700$ $=0,43$ ( > 0,3, syarat SNI 03-2847-02 ps. 23.3.1). Jadi ukuran balok 300/700 dapat digunakan. Dari tabel 1 diperoleh nilai $\rho$ sebesar 0,0122. Luas tulangan yang diperlukan $A_{s}=\rho . b . d=0,0122 \times 300 \times$ $625=2287,5 \mathrm{~mm}^{2}$ sehingga dapat dipasang 5D22 + 2D16 $\left(\mathrm{A}_{\mathrm{s}}=2302 \mathrm{~mm}^{2}\right)$.

Secara umum, prosedur desain elemen balok beton bertulangan tunggal berdasarkan rasio tulangan balanced dapat mengikuti diagram alir sebagaimana digambarkan dalam Gambar 4.

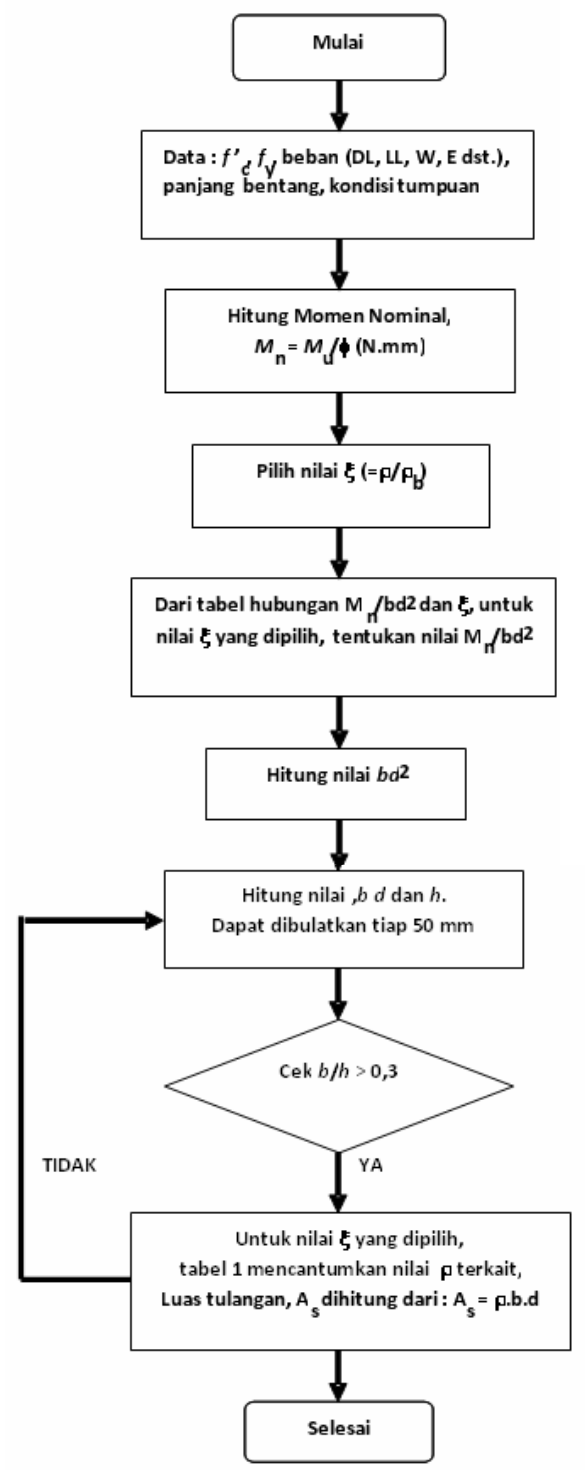

Gambar 4 Diagram Alir Desain Balok Beton Bertulangan Tunggal 


\section{SIMPULAN}

Dari hasil uraian di atas, dapat diambil beberapa kesimpulan sebagai berikut. Pertama, perencanaan balok beton bertulangan tunggal dapat dilakukan secara cepat dengan menggunakan dasar rasio terhadap $\rho$ balanced. Kedua, hasil desain dapat dipastikan tidak melebihi dari $\rho$ maksimum yang disyaratkan dalam SNI 03-2847-2002, yaitu sebesar 0,75 $\rho_{\mathrm{b}}$, karena perencana dapat mengambil nilai $\rho$ jauh di bawah $0,75 \rho_{\mathrm{b}}$ secara langsung. Ketiga, persyaratan tulangan minimum telah terakomodir dengan telah diperhitungkannya nilai $\xi$ minimum yang boleh diambil.

\section{DAFTAR PUSTAKA}

Badan Standarisasi Nasional. (2002). Tata cara perhitungan struktur beton, SNI 03-28467-2002, Bandung: Departemen Permukiman dan Prasarana Wilayah.

Cormack, J. C. (2004). Desain beton bertulang, Jakarta: Erlangga

Hasooun, M. N., and Manaseer A. A. (2005). Structure concrete theory and design, Canada: John Wiley \& Sons Inc.

Nawy, E. G. (2005). Reinforced concrete a fundamental approach, New Jersey: Pearson Education Inc.

Nilson, A. H., Darwin, D., and Dolan, C. W. (2003). Design of concrete structures, New York: Mc.Graw Hill. 